\title{
Balloon dilatation of stenosed Blalock-Taussig shunts
}

\author{
SHAKEEL A QURESHI, * ROBIN P MARTIN, * DAVID F DICKINSON, $\dagger$ \\ STEWART HUNTER‡ \\ From the Departments of Paediatric Cardiology, ^ Royal Liverpool Children's Hospital, Liverpool; \\ $\dagger$ Killingbeck Hospital, Leeds; and $\ddagger$ Freeman Hospital, Newcastle Upon Tyne
}

SUMMARY Three patients with complex cyanotic congenital heart disease, who had previously undergone Blalock-Taussig shunt operations, developed severe stenoses at the pulmonary anastomosis of the shunts. All were successfully treated with balloon dilatation, which can thus be considered an effective alternative to reoperation.

When a Blalock-Taussig shunt becomes stenosed the therapeutic options include the creation of another systemic-pulmonary artery shunt or, if suitable, correction of the underlying cardiac malformation earlier than planned. Balloon angioplasty has been used for successful dilatation of a wide range of arterial stenoses and new applications continue to be reported. We report the successful dilatation of severely stenosed Blalock-Taussig shunts in three children with complex cyanotic congenital heart disease.

\section{Patients and methods}

Three children underwent percutaneous balloon dilatation of stenosed Blalock-Taussig shunts. The group consisted of a three year old boy with Down's syndrome, tetralogy of Fallot, and complete atrioventricular septal defect (patient 1); a nine year old girl with a common atrioventricular valve connection to a morphologically left ventricle and pulmonary atresia (patient 2 ); and a 12 year old boy with dextrocardia, situs solitus, atrioventricular concordance, a straddling right atrioventricular valve, ventricular septal defect, transposition of the great arteries, and pulmonary atresia (patient 3 ).

Patient 1 developed cyanotic spells at the age of two years three months and had a right BlalockTaussig shunt operation. Seven months later he became more cyanosed and shunt angiography showed a discrete and severe stenosis at the anastomosis of the shunt (fig 1 ).

Present address and requests for reprints to Dr Shakeel A Qureshi, Department of Paediatric Cardiology, Guy's Hospital, St Thomas Street, London SE1 9RT.

Accepted for publication 24 January 1989
Patient 2 had a right Blalock-Taussig shunt opera- $\circ$ tion when she was one year old. A year later, because of increasing cyanosis, a left Blalock-Taussig shunt 3 was performed. At the age of eight years, she became more cyanosed. Angiocardiography and shunt $\overrightarrow{0}$ angiography showed moderately severe atrioven- 0 tricular valve regurgitation and severe stenosis at the anastomoses of both the shunts.

Patient 3 had a right Blalock-Taussig shunt at the age of one month. Five years later, a left modified Blalock-Taussig shunt with a $6 \mathrm{~mm}$ diameter

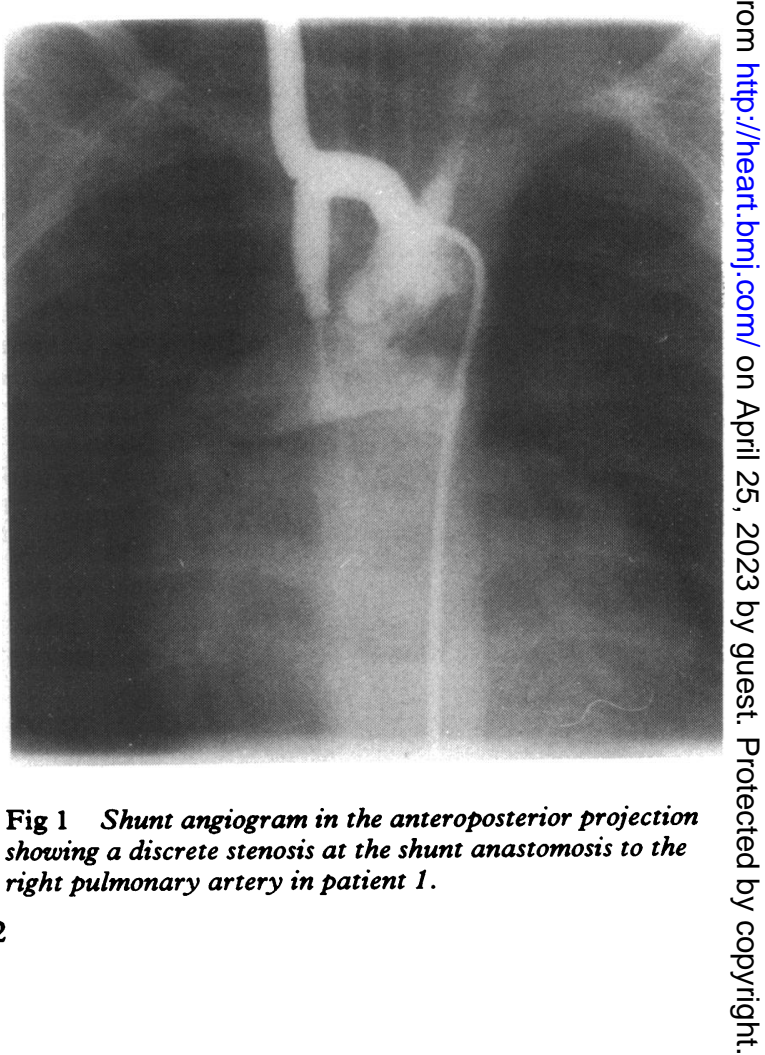


polytetrafluoroethylene graft was performed because of increasing cyanosis. When he was 12 years old further cyanosis prompted shunt angiography, which showed severe stenosis of the anastomosis of the right shunt and a patent and unobstructed left modified shunt.

\section{TECHNIQUE OF BALLOON DILATATION}

Cardiac catheterisation was performed percutaneously by the femoral venous and arterial routes under general anaesthesia in all cases. A 6 French multipurpose catheter was passed from the femoral vein and placed in the right atrium for access. A 5 French multipurpose end hole catheter was then passed retrogradely through the femoral artery and placed at the origin of the Blalock-Taussig shunts. Shunt angiography was performed to confirm the site and the severity of the stenoses and to measure the diameter of the shunt. The external dimension of the catheter was measured on a still frame of the cineangiogram and the magnification factor was calculated by dividing this by the actual external diameter of the catheter. The diameter of the midportion of the subclavian artery shunt was then measured on a still frame and this value was divided by the magnification factor previously obtained to give the actual diameter of the shunt. We selected a balloon with an external diameter 1-2 mm greater than the shunt diameter.

A $175 \mathrm{~cm}$ long 0.020 inch $(0.5 \mathrm{~mm})$ diameter steerable exchange guide wire was then used to manipulate the end hole catheter across the stenosis into the distal pulmonary artery on the side of the shunt in patients 2 and 3 and into the pulmonary trunk and through the pulmonary valve into the right ventricle in patient 1 . Heparin (50 units $/ \mathrm{kg}$ ) was given intravenously to each patient. The guide wire was kept in position as the catheter was exchanged for a Schneider Medintag balloon catheter of appropriate balloon diameter. In patients 1 and 3 a balloon catheter with an external diameter of $6 \mathrm{~mm}$ was used for dilatation, and in patient 2 a balloon with an external diameter of $8 \mathrm{~mm}$ was used to dilate the right shunt and one of a $10 \mathrm{~mm}$ diameter for the left shunt. The balloon was inflated two or three times at each site to a pressure of $404 \mathrm{kPa}(4 \mathrm{~atm})$ for $10-15$ seconds and then deflated. The guide wire was kept in position as the balloon catheter was exchanged for the end hole catheter and shunt angiography was repeated.

\section{Results}

There were no complications during the procedure in the three patients. At the end of the procedure, the foot pulses were easily palpable. Repeat shunt angiography immediately after balloon dilatation showed successful relief of the stenoses (fig 2) in each patient. Good flow was demonstrated through the shunts into the pulmonary arteries.

During a follow up of 6-16 months all three children remained adequately palliated. They were pink and had loud shunt murmurs.

\section{Discussion}

Patients with complex cyanotic congenital hear $\vec{P}$ disease may occasionally be unsuitable for surgicat correction (as in patients 2 and 3), and therefore are considered for palliative surgery only. If, however they are suitable for correction (patient 1), then is? may be preferable to delay operation until the age of 5-10 years. Palliation, consisting of a systemic to pulmonary artery shunt, is then performed to help the patients attain the appropriate age and size for correction.

Early or late occlusion occurs in approximatel $10 \%$ of Blalock-Taussig shunts, ${ }^{12}$ but the incidence of discrete stenosis of the shunt anastomosis, whicho may be difficult to detect clinically, is unknown. If the shunt becomes occluded, a further shunt may be necessary, but the development of a discrete stenosi at the anastomotic site may be amenable to balloor dilatation.

Balloon angioplasty has been increasingly con $\frac{8}{2}$

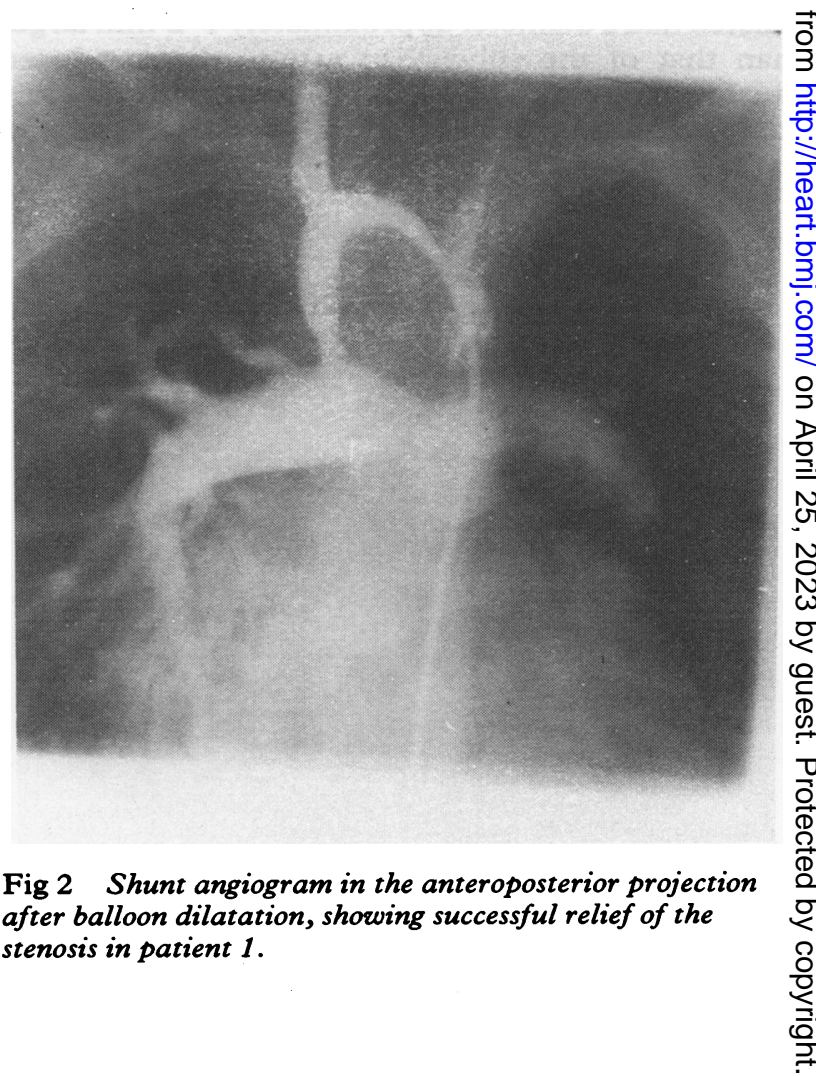


sidered as the standard procedure for treating recoarctation of the aorta after previous operation, ${ }^{3-5}$ where the restenosis is thought to be caused by a dense fibrous tissue reaction. A Blalock-Taussig shunt may become stenosed by a similar tissue reaction at its anastomosis into the pulmonary artery. Therefore balloon dilatation may be a useful treatment for stenosed shunts. To date there has been only one report of successful balloon dilatation of a stenosed Blalock-Taussig shunt. ${ }^{6}$

In patient 1 flow into the pulmonary circulation occurred through the pulmonary valve and through the Blalock-Taussig shunt; in patients 2 and 3 it occurred only through the left and right shunts. Thus flow into the pulmonary circulation was maintained during balloon inflation and any haemodynamic disturbances were prevented. In patients with shuntdependent pulmonary blood flow, shunt dilatation could be more hazardous-possibly resulting in hypoxia, metabolic acidosis, and arrhythmias. Rapid placement and inflation of the balloon catheter would be required.

Generally, an exchange wire of the diameter appropriate for the balloon catheter is used. However, the use of a steerable guide wire makes it technically easy and quick to cross the severe anastomotic stenoses. This facilitates the passage of the balloon catheter over the stiffer portion of the guide wire into the shunt. We used a balloon that when inflated had a diameter approximately 1-2 mm larger than that of the subclavian artery; this produced satisfactory results in all the patients with no early complications. Further follow up is necessary to
Qureshi, Martin, Dickinson, Hunter
determine whether late complications such as aneurysm formation or restenosis occur.

We believe that balloon dilatation of stenosed Blalock-Taussig shunts is a reasonable and safes alternative to reoperation in those patients who areo unsuitable for surgical correction and in those incwhom the correction needs to be delayed.

\section{References}

1 Arciniegas E, Farooki ZQ, Hakimi M, Perry BL, Green EW. Classic shunting operations for congenital cyan- $-\overline{7}$ otic heart defects. J Thorac Cardiovasc Surg 1982, 84:88-96.

2 Stewart S, Alexson C, Manning J, Oakes D, Eberleyp SW. Long term palliation with the classical Blalock t Taussig shunt. J Thorac Cardiovasc Surg 1988;0 96:117-21.

3 Lock JE. Catheter intervention: balloon angioplasty. In: Lock JE, Keane JF, Fellows KE, eds. Diagnostic and interventional catheterization in congenital heart disease. Boston: Martinus Nijhoff, 1987:91-110.

4 Kan JS, White RI Jr, Mitchell SE, Farmlett EJ, Donahoo EJ, Gardner TJ. Treatment of restenosis of $\square$ coarctation by percutaneous transluminal angio-O plasty. Circulation 1983;68:1087-94.

5 Saul JP, Keane JF, Fellows KE, Lock JE. Balloon dilatation angioplasty of postoperative aortic coarcta-O tion [Abstract]. J Am Coll Cardiol 1986;7:117A.

6 Fischer DR, Park SC, Neches WH, et al. Successful $=$ dilatation of a stenotic Blalock-Taussig anastomosis by percutaneous transluminal balloon angioplasty. Am J Cardiol 1985;55:861-2. 